\title{
THE IMPORTANCE OF LEISURE TIME MUSICAL ACTIVITIES IN CHILDREN'S EDUCATION AND DEVELOPMENT AS ESTABLISHED BY REFORMERS OF THE MUSIC PEDAGOGY
}

\author{
M. Velikova* \\ Department Social Pedagogy and Social Work, Faculty of Preschool and Primary School Education, \\ Sofia University "St. Kliment Ohridski”, Sofia, Bulgaria
}

\begin{abstract}
Learning combined with arts builds long lasting social skills and educate on tolerance, creativity and discipline. This combination when used in work with children, helps the children to develop ability for better self-expression, building up confidence, concentration, integration in the group, developing imagination, recognizing good and beautiful, increase their chances for success in life. The music is very close to the emotional nature of children and therefore could stimulate and develop their mental and physical abilities. The focus of this report is addressed to the importance of musical activities for children's development.
\end{abstract}

Keywords: musical activities, musical interests, needs of music, children's development

\section{INTRODUCTION}

Music takes an important place and occupies significant time in man's life. Irrespectively where we live and what we do music is an integral part of our daily activities This is esecially true for young adults and children. However, whether we take full advatege of it today is still debatble? Various studies show the many positive effects of practicing musical activities in human development. It is well accepted today that the use of music and musical activities during the educational process contributes to children's emotional, social and cognitive development. Music has an important impact in the children's development in terms of language skills, literacy, numeracy, intellectual development, stimulating creativity, physical, personal and social development. Classes with musical activities were shown to contribute to the overall growth of the child.

Music is loaded with intellectual, emotional and social content. It has a different meaning for everyone who performs or listens. The arts have the power to educate and therefor music has the capacity to support the educational process if used

\footnotetext{
${ }^{*}$ Correspondence to: Milena Stefanova Velikova, PhD Student in Department Social pedagogy and social work, Faculty of preschool and primary school education, Sofia University "St. Kliment Ohridski", email:mi.velikova@gmail.com
}

rational. However, the leisure time can have two faces and be a double-edged sword. On one hand it provides the opportunity for education, intellectual development, building social contacts, personal development and on the other hand it may provoce destructive emotions, activities that destroy personality, aggression and violence towards other individuals or objects. Therefore, it is essential to show to children how to use their leisure time and to give them directions and guidelines in order to establish the triad: values leisure time - education.

Pedagogy of leisure time is "community of four educational and instructive objects", as defined by $\mathrm{H}$. Opashovski. This area of pedagogy connects and supports social, cultural, creative and communication education - therefor the music classes and other activities related to various arts should be an integral part of children leisure time. The subject of children's leisure time, priorities and trends in its enrichment and adecuate use is directly linked to the question of their preparation for life and their future and also to their current socialization, education and cultural values. The most important feature of leisure time is that anyone can use it the way they like according to their personal material or spiritual needs. (1) Music is one of the arts which if used efficently in children's leisure time can help their 
development. Several profecional music teachers developed reformist ideas on how to translate "practicing music" into a "positive impact" on children's daily live. These ideas are now practiced all over the world. Over the years, the work of these reformers provides very favorable results for the upbringing and development of children. One of the varieties of reform movements in pedagogy from the second half of the nineteenth and early twentieth century uses art in the process of education and training, and even to transform education into art training. (2)

\section{MATERIALS AND METHODS}

The aim of this article is to present an overview of the world leading music pedagogues - reformers and to show to what extent education and traininglearning benefit from music. This study will explore and analyze the work of the reformers on application of music as a tool in education of children. Another focus of the current work is children's leisure time. It is crucial that this time is occupied with appropriately selected and managed activities to assist young people social, cultural, creative and communicational education. This research draws attention on the importance of the arts in the educational-learning process and highlights the significance of cultural consumption in children's leisure time for their full development as individuals.

The research method used here is analysis of the literature in the field of pedagogy of leisure time, music psychology and music pedagogy. The work of professional music teachers who worked in the second half of the nineteenth and early twentieth century was studied. Their research is of high scientific and practical significance and is implemented in music education and music pedagogy. They managed to establish themselves as experts in the field and have followers today who not only keep their ideas and methods of working with children through musical activities but also continue to work through them. The summary and conclusions in this paper are based on both (1) analysis of the work of reformersexperts and (2) observations and impressions made by the author during practical work with children using musical activities. The following is a summary of the points which the developmental psychology of music has so far indicated:

1. The effect of musical experience begins right from birth and, perhaps, even prenatally.

2. Children's early experiences with music should be personal, active, physical, and concrete.

3. Learning takes place through a sequence of perception - response - cognitionconceptualization.

4. The skill of listening is basic to all musical activity.

5. The 'expressive' elements of music are most easily perceived and discriminated followed by duration, pitch, and finally, harmony.

6. Singing and moving should precede the playing of instruments.

7. Teaching of notational skills should be preceded by aural and vocal experiences.

8. Children form concepts about music when they have had many experiences with its elements and have appropriate vocabulary. (3)

These statements are in aggrement with the perspective of Zoltan Kodaly (1882 - 1967) regarding the influence of music on children and education through music educators. His approach is broadly use nowadays and practiced by teachers inspired by the work of Kodaly and his followers. According to Zoltan Kodaly, the musical education of the child begins not from the moment of his/her birth but when in the womb of their mother. He said: "...on the question, when should the musical education of the child begin, I answered accidentally, nine monthes before their birth." Kodaly and his followers support the idea of the importance of an active physical connection with music. Very often during the training, a variety of games are used to explain things and situations. Music games are close to human nature. The musical experience of children must be enriched with many songs as the music is call "the first acoustic phenomenon". Since the basis of the Kodaly method is singing, it's obviously a musical activity of prime importance. Even if the student doesn't study a musical instrument later, through singing he/she'll get closer to the understanding of music, and can become acquainted with instrumental music by singing themes, that is to say, by means of active involvement. One of the basic principles of Kodaly's conception is tht everyone should use the most accessible musical instrument, one's own singing voice, in the process of musical discovery. (4) According to Kodaly it should be primarily folk-music, every nation's own folk songs. The child has to learn his musical mother tongue first.

Erzsebet Szonyi wrote that the results of application of Zoltan Kodaly's method in music education are surprising. They confirtm his theory that increased music education has a positive influence on the development of both the child's intelectual and emotional world. (4) The daily music lessons very soon bring out the sense of rhythm in young children and teach them to sing clearly, to interpret correctly. Attantion that has to be paid to the tempo and dynamics of music refines their power of comprehension and bring out their ability to express themselves. For this reason the child develop a richer fantasy and his work in other subjects is also more inspired. Quick associatins and concentrated attention develop mathematical abbility, and their sense of 
In her practice Klara Kokas worked with different

Overal the method of Zoltan Kodaly aims:

- To create a balance between instruction for professional musicians and training guide to the public, ie to make music accessible to everyone;

- To provide a uniform basic for musical education for every child up to age of 14 , as this is of great importance for general education;

- Singing to be a tool to deliberately exploit the possibilities for teacher education in music in the process of shaping.

"Those who have had the opportunity to put into practice some of Kodaly's ideas realize that his is a pedagogy of harmony: harmony between music and the child. The role of the teacher is to understand better both the nature of music and the nature of the child in order to bring together those experiences which allow music and children to touch one another so that the harmony can happen.” (3)

One of the followers of the Kodaly is his student Klara Kokas (1929 - 2010). Working with children for nearly two decades, she found suitable and effective method to work with them and said that her discoveries have come to her through the work with children. It is easy to adapt to music; one can mark the rhythm with one's feet, skip and lean with the tune, turn with its turns, vary with its variables. Music starts the ball of our imagination rolling: it sets the tempo of the movement and traces out the limits of its progress. Music always shows where the movement starts out from, and also where it ends. Individual imagination in this case manifests itself in the originality of movements. When they move by themselves, without direction, plan or choreography, children listen to the music differently: they do it from deep down, from the subconscious, from the bottom of their heart. (5) "Inspired music can be a physical sensation: it moves you, perhaps it can even be touched. It resounds in you, below and above you, all around you." (5)

Klara Kokas remembered: "Kodaly sent me to organize music education for the first time at Sszombathely, Hungary, in a primary school through daily classes specializing in singing and music. Impressive results were soon reach with children who had music lessons every day. Both parents and teachers of our pupils discovered that - thanks to increased number of music lessons the children's performance in other subjects improved as well: in math and spelling for instance. Their attitude to learning changed; they become more independent and confident. When I saw the achievement of my children, I began to study the transfer effect of music education." (5) children - who rush to music with heart and soul, as well as with those with special educational needs. The mentally and physically handicapped students are not the only ones to seek the path that leads them to the freedom of soul healing. Adults in full possession of their physical and mental capacities are yearning for it just as much; they are the ones who, under the magic of Bach or Mozart's harmonies, discover their hidden reserves and accept their worries locked up in their subconscious. (5)

Another follower of Zoltan Kodaly is Professor Katalin Forrai (1926 - 2004). Her wealth of experience as a teacher is reflected in her work as a pedagogical specialist and researcher. She has developed national curricula and music programs for children as well as for teacher education students and for serving teachers. One of the most noteworthy of Katalin Forrai's pedagogical accomplishments is her work implementing Kodaly's philosophy of music education.With Kodaly guidance and friendship, she developed methods and materials for pre-school children in Hungary that provide a model for pre-school curricula around the world. She undertakes this work in the spirit of the Kodalyian notion that the development of children's musical abilities must be started nine months before birth - moreover, nine months before their mother's birth! (6)

Another reformer in music pedagogy is the composer Karl Orff. Compser Carl Orff (1895 1982) and his collaborator Gunild Keetman (1904 - 1991) developed a holistic educational concept (known as Orff Schulwerk) whereby students learn through active music-making. Schulwerk as a pedagogy and a philosophy connects the emotional and cognitive aspects of learning and puts the child at the center. Through the musical activities children do not only have fun but also explore the world and educate. The combination of emotional and cognitive aspects of learning is what makes this approach of pedagogy interesting. The trainig and education of a child begins with what he or she can do best - singing, playing instruments, game, movment and dance. Through creating, improvising, exploring and experimenting, the children arrive at a deeper understanding of music. Adding movement, drama, and visual arts enriches the learning experience. In these lessons one will see how a poem might inspire a drawing, a dance might lead to a collage. This way children experience concepts from inside out and outside in - they become adept at making communal music and dance. (7) This is extremely valuable because typical for adolescents is continuous striving to communicate and contact others of their age. (8)

In Orff Schulwerk, teachers are not bound to use 
the same curriculum: we prefer to describe our work in terms of 'ideas' and 'processes' instead of as a method. As Carl Orff said: "Those who look for a method or a ready-made system are rather uncomfortable with the Schulwerk; people with artistic temperament and a flair for improvisation are fascinated by it. They are stimulated by the possibilities inherent in a work which is never quite finished, in flux, constantly developing." (9) Orff Shulwerk is method for self-discovery through making music and dance. It is successfully applied for both natural gifted children and also for those who are less inclined to sing, dance or play a musical instrument. Orff Shulwerk provides diverse spectrum of ideas and ways of expressing that provide opportunities for everyone.

Music teacher Sofia Lopez - Ibor (1962) examined and used the practical concept of integration of the arts using music and dance as main approach in the classroom. She knows and support children, understand how they think and play.

Sofia Lopez said: "Those children, and countless others, taught me my most important lessons as a teacher:

- Observe how the children are thinking and ask what they're thinking.

- Watch how they react.

- Accept their response and try out their ideas.

Once you understand that children indeed have interesting, and often, brilliant ideas, your teaching will change." (7) In her work with children Sofia Lopez - Ibor combines music, poetry, dance, visual arts in an interdisciplinary way. Visual and performing arts affect our emotions and senses. We can be moved by a piece of music or art by simply listening or looking. Music is the art of thinking with sunds organized in rhythm, melodies, harmonies, texture, forms, and timbre. Art has similar elements of color, form, design and texture while dance and language have perimeters in common with music and art. (7)

Certainly music interacts with other arts. However, music has a great advantage and leading role as it has the ability to penetrate into deep layers of the individual personality. Swiss music teacher, composer and writer Emile-Jacques Dalkroz (1865 - 1950) built his system of education of children based on music and movement. He belives that music has beneficial impact in harmonious development of children. He determined the first years of children's lives as very important for their musical education. The Dalcroze method, also known as Dalcroze Eurhythmics, incorporates the basic elements of music - rhythm, melody, harmony — with body movement, to provide a multi-dimensional approach to music learning. Unlike most traditional methods, improvisation is a major component of the Dalcroze approach and one of its three aspects:

1. Eurhythmics trains the body in rhythm and dynamics

2. Solfege (sight singing) trains the ear, eye and voice in pitch, melody and harmony

3. Improvisation brings all elements together according to the student's own invention, in movement, with voice, at an instrument. (10)

Beyond musical intelligence, the Dalcroze approach engages and exercises several other aspects of intelligence. Musical games and experiments engage logical thinking. Eurhythmics appeals to kinesthetic and spatial types of learners. The social quality of music-making develops communication, feeling, and empathy. It has the physicality of sports, aesthetic appeal of the arts, and is mentally challenging, for all ages. (10)

The Dalcroze concept of improvisation is close to the nature of childhood play. Improvisation frees a child to relate directly and spontaneously to music within a range of musical knowledge. Improvising with full-body movement, singing or playing an instrument, helps the child internalize complex elements of rhythm, pitch, tone and dynamics without having to read a musical score. Through improvisation, composing becomes a personal and immediate creative act. A child enhances his creative spirit through improvisation and carries that spirit into his daily life. (10)

Dalcroze Eurhythmics is a method of learning and experience of music through movement. Emotions evoked by music are expressed in movements reflective the music. Thus it becom the means of formation of motor habits and skills with the help of music. It contributes to the development of attributes such as agility, speed, fluency, expression, ensemble during the performance.

Expression of music through the motions is a leading technique in the work of Prof. Veronika Cohen (Israel). Besides being a teacher, she explored the musical creative thinking in children and the relationship between movement and music knowledge. She has developed a pedagogical approach to facilitate listening to music using sensations or "Musical mirrors". They represent movements of the arms, reflecting music ascending and descending movement of music, rhythm changes, changes in harmony, phrasing of the music. The teacher performs the "mirror" while children mostly listen to music and later mimic the movements of the teacher. The "music mirrors" used as a convenient tool to translate music information without words. 
Veronika had observed that many kindergarden children prefer to accompany their music making with overt movement, even locomotion. However as the children's musical production became more natural they resorted less and less to extraneous movement. This belief in movement as the source of musical thinking received its major support from Piaget's theory of the development of logical thinking. Indeed just as in the Piaget's theory, the roots of logical reasoning are in psycho-motor action, so the roots of musical cognition/ feeling are in kinesthetic gestures. My observations led me to see that the smallest musical entity is not a sound but a complete musical gesture. (11)

Knowing that the mirror is such a powerful means for drawing the viewer into the music or pushing the viewer away from it should make teachers approach mirrors with respect, investing the greatest possible effort and their best musicianship in order to discover the appropriate mirror for each piece of music they present. (11)

Another teacher who made a significant impact in teaching music to children is the violinist, philosopher and humanist Shinichi Suzuki (1898 1998). He began to apply the basic principles of language acquisition to music learning and called his method the "mother-tongue" approach. The ideas of parent responsibility, loving encouragement, constant repetition, etc., are some of the special features of the Suzuki approach. The Suzuki method is based on the principle that all children possess ability and that this ability can be developed and enhanced through a nurturing environment. All children learn to speak their own language with relative ease and if the same natural learning process is applied in teaching other skills, these can be acquired as successfully. (13)

The important elements of the Suzuki approach to instrumental teaching include the following:

Early Beginning:

The early years are crucial for developing mental processes and muscle coordination. Listening to music should begin at birth; formal training may begin at age three or four, but it is never too late to begin.

The importance of listening to music:

Children learn words after hearing them spoken hundreds of times by others. Listening to music every day is important. So the child knows them immediately.

Learning to play before learning to read:

Constant repetition is essential in learning to play an instrument. Children do not learn a word or piece of music and then discard it. They add it to their vocabulary or repertoire, gradually using it in new and more sophisticated ways.

- Parent involvement:

As when a child learns to talk, parents are involved in the musical learning of their child.
They attend lessons with the child and serve as "home teachers" during the week. One parent often learns to play before the child, so that she understands what the child is expected to do. Parents work with the teacher to create an enjoyable learning environment.

- Encouragement:

As with language, the child's effort to learn an instrument should be met with sincere praise and encouragement. Each child learns at his/her own rate, building on small steps so that each one can be mastered. Children are also encouraged to support each other's efforts, fostering an attitude of generosity and cooperation.

- Learning with other children:

In addition to private lessons, children participate in regular group lessons and performance at which they learn from and are motivated by each other.

- Delayed reading:

Children learn to read after their ability to talk has been well established. In the same way, children should develop basic technical competence on their instruments before being taught to read music. (14)

Dr. Suzuki himself always said that his wish was to foster the human qualities in the child. At every opportunity he called on politicians, teachers and parents to ensure that the full potential of every child is developed: "I want - if I can - to get education changed from mere instruction to education in the real sense of the word-education that inculcates, brings out, develops the human potential, based on the growing life of the child. That is why I am devoting my efforts to furthering Talent Education: what a child becomes depends entirely on how he is educated. My prayer is that all children on this globe may become fine human beings, happy people of superior ability, and I am devoting all my energies to making this come about, for I am convinced that all children are born with this potential." (13)

Similar to the Suzuki's method is the work and approach of Edwin E. Gordon (1927). He is well known researcher, teacher and writer of music psychology "All learning begins with the ear, not the eye. It is the same with process of learning music. Although music is not a language, we can notice the same process when we learn music and when we learn a language. The stage are as follows: first we learn to listen, then to speak or to perform what we have heard, after that we learn to read what we speak or perform, and finally to write what we read or perform. It is to be observed that the process of learning music is the same as during learning a language." (15)

His Music Learning Theory is an explanation of how we learn when we learn music. Based on an extensive body of research and practical field 
testing by Edwin E. Gordon and others, Music Learning Theory provides the music teacher a sequential and comprehensive method for teaching musicianship through audiation, Gordon's term for thinking music in the mind with understanding. Music teachers of all stripeselementary general, instrumental, vocal, the private studio-can use learning sequence activities to develop their students' tonal and rhythm audiation. Skills thus learned can then be applied to all manner of classroom activities, enabling students to draw greater meaning from the music they listen to, perform, improvise, and compose. The objective is to help students become independent musicians and musical thinkers. (16)

The process of learning music is much the same as that for language. In learning to speak, children first listen. From the time of birth, and even before, they are surrounded by the sounds of language. They absorb these sounds and become attuned to the language of their culture. Soon after, children begin to imitate. They receive much praise and are encouraged to 'babble', even when their sounds do not make sense to adult listeners. Then they begin to think in the language. Words and phrases start to have meaning to them. Next, children improvise in the language. They make up their own phrases and sentences that are organized in a logical manner. They can engage in conversation. Finally, after several years of developing their ability to think and speak, children are taught how to read and write. Only after all these skills are well in place is grammar, the theory of sentence construction, introduced. (16)

As Zoltan Kodaly, Edwin E. Gordon said: "One's potential to learn is never greater than at the moment of birth. The early years of life are crucial for establishing a foundation for lifelong music development. A child's musical experiences from birth to age five have a particularly profound impact on the extent to which she/he will be able to understand, appreciate, and achieve in music as an adult. Children must be exposed to a rich variety of music during these years in order to develop the necessary readiness for formal music learning when they are older." (16)

The method of Edwin E. Gordon of teaching music is suitable for children of preschool and primary school age, but can be applied in work through music with children of different ages. There are many common features with the methods of Suzuki, Dalcroze, Kodaly and Orff. In all these methods students build a solid base of phonetic and performing skills by singing, rhythmic movements, tonal and rhythmic exercises before being taught notation and music theory.

The methods of working with children through music reviewed in this paper showed that the work of educators-reformers in the field of music education and music pedagogy has an important contribution in strengthening the role of music in education and its beneficial influence on the development of personality.

\section{CONCLUSION}

Based on the approaches (reviewed in the article) developed by the world-leading reformers in the field of music education on teaching music in the learning process and during leisure activities of children, the experience of their followers and the author's experience and observation gained while working with children led to the following conclusions:

- In world practice there are useful approaches of working with children through music, which support their education and personal development. Research and practice of educators prove this assertion;

- Music classes can be practiced by any child or adult of any age without intentionally chosing music as a career path. Classes in music are accessible to everyone.

- The music occupies an important place in everyday life, it can be channeled and used for personal development activities. Leasure time is that part of the day that can be used used in this manner.

- Musical activities have a very strong influence on children's development, which in turn assists their improvment in other areas (subjects).

- Although that many of the reviewed programs and methods are developed for music education, the musical activities have a favorable impact on the overal development and abilities of children and support their work in other areas of life.

- The reviewed approaches demonstrate that working through music is connected to the natural human need of movement; Music contribute to the development of both physical and spiritual forces of the child.

It is key to practice musical activities as a part of the education system or leasure time of children and their parents. It is important to take advantage of the resources that leisure time can offer for children development. Another important step towards successful change is that parents should practice musical activities together with their children (at home). This can be accomplished by organizing training for parents on how to sing and play with their babies and children. Most importantly, however, is to teach parents how to identify children's interests and how to use their talents in the educational-learning process.

In conclusion, this article follows the philosophy of music education based on aesthetics: "Music 
can change the way children feel, think and act... Music enables children to define themselves in relation to others, their friends, colleagues, social networks and to the cultures in which they live... The teaching of music deepens and extends everyday experiences, providing new opportunities and forging important links between the home, the school and the outside world." (17)

Long years practice of teachers- reformers in musical education showed how successful music can be used in children's daily lives. Today their followers continue to prove that working with musical activities positively affects the overall growth of the child and assist the educational process.

\section{REFERENCES}

1. Boyadjieva, N., Pedagogy of leisure time. Academic fields of social pedagogy, University Publishing House "St. Kliment Ohridski ", Sofia, p. 327-362, 2014.

2. Boyadjieva, N., Education through art. Sofia. 1994.

3. Sinor, J., Musical Development of Children \& Kodály Pedagogy. Kodaly Envoy, Spring 2014, Vol. 40 Issue 3, p. 17-20, 2014.

4. Szonyi, E., A summary of the Kodaly Method. Kodaly Seminar, Kecskemet 1970, Kodaly Institut, 1970.

5. Kokas, K., Joy through the magic of music. Budapest: Akkord Music, p. 11-15, 1999.

6. Csebfalvy, E., Sims, W., Personalities in World Music Education No 15 - Katalin Forrai. Music Educ., p. 25-38, 1992.

7. Lopez-Ibor, S., Blue is the sea. California, p. 3-6, 2011.
8. Boyadjieva, N., Communication in the teenager's leisure time - trends and specifics. Primary Education, vol. 11, 1999.

9. Orff, C., The Schulwerk: Its Origins and Aims. Translated by Arnold Walter. Music Educatiores Journal/ Vol. 49.

10.Butera, K., What is the Dalcroze Teaching Method. 06.01.2012. Last available on 28.06.2015, <https://www.sfcv.org/tipsadvice/what-is-the-dalcroze-teaching-method>

11.Cohen, W., Musical mirrors and Mirror Neurons. International Scientific Conference "Art and Education - Traditions and Modernity", Vol. 1. Academy of Music, Dance and Fine Arts. Plovdiv, p. 61-72, 2015.

12.Opashovski, H., Pedagogy of leisure time. Anthology of Theory of Education. Race. L. Dimitrov, Sofia, p. 320-329, 1997.

13.International Suzuki Association. The Suzuki Method. Last available on 28.06.2015, <http://internationalsuzuki.org/method.htm>

14.Suzuki Association of the Americas. About the Suzuki Method. Last available on 28.06.2015, $<$ https://suzukiassociation.org/about/suzukimethod/>

15.Gordon, E., Learning Sequences in Music. Skill, Content and Patterns. A Music Learning Theory, Study Guide. GIA Publications, Inc. Chicago, p. 25-40, 1997.

16.Dalby, B., The Gordon Institute for Music Learning. Last available on 24.06.2015, <http://giml.org/mlt/>, p. 2, 7, 27.

17.Qualifications and curriculum Authority: The review of the National Curriculum In England: The consultstion materials. London: QCA. (162), 1999. 
VELIKOVA $M$.

Trakia Journal of Sciences, Vol. 13, Suppl. 1, 2015 